\title{
As obras de Graciliano Ramos e Guimarães Rosa nos rodapés de Wilson Martins e Franklin de Oliveira
}

\author{
André Barbosa de Macedo'
}

\section{Os dois críticos}

Wilson Martins, depois de ter começado como secretário de um jornal em Ponta Grossa (Paraná), iniciou, em 1942, com apenas 21 anos, colaboração por meio de textos críticos para o jornal O Dia, de Curitiba. O volume de textos, publicados esparsamente e, depois, como rodapé, aumentaram significativamente nos anos seguintes. ${ }^{2}$ Também formado em direito, como a maioria dos críticos de jornal, enquanto escrevia tais rodapés, Martins realizou estudos literários em Paris (1947-1948), os quais resultaram em tese de concurso na Universidade Federal do Paraná - esse foi um passo que críticos de rodapé como Milliet, Álvaro Lins e Franklin de Oliveira não chegaram a dar (assinale-se que Lins defendeu tese sobre Proust, mas isso se deu no âmbito do Colégio Pedro II, portanto, apesar de semelhante, não se tratava propriamente de estudo universitário) (Lins, 1956). Assim, entre 1952 e 1962, o crítico foi professor de língua e literatura francesa, tendo exercido também a função de juiz de direito. Em 1954, em substituição a Milliet, tornou-se o crítico titular de O Estado de S. Paulo, até 1974, ano em que se desentendeu com os proprietários. ${ }^{3}$ Antes de aí interromper as atividades como crítico de rodapé, Martins transferiu-se (1962) para universidades norte-americanas e, depois de passagens curtas por duas outras universidades, permaneceu na Universidade de Nova York até 1992 (SEFFrin, 2001; MARTINS, 1952). ${ }^{4}$

Doutor em Literatura Brasileira pela Universidade de São Paulo (USP), São Paulo, sP, Brasil. E-mail: andre.macedo@usp.br

2 A data mais provável em que Martins se tornou crítico titular de O Dia foi 4 de fevereiro de 1943. Cf. Arquivo de Wilson Martins, Universidade Estadual de Ponta Grossa, Ponta Grossa (PR).

3 Os donos do jornal teriam sugerido, em 1974, a não publicação de um rodapé, o que não foi aceito pelo crítico.

4 Ver também Arquivo Pessoal de Wilson Martins, Universidade Estadual de Ponta Grossa, Ponta Grossa (PR). 
Já Franklin de Oliveira, que iniciou o curso de direito, mas o abandonou, ${ }^{5}$ foi um dos sucessores de Álvaro Lins no Correio da Manhã, e dividiu o rodapé com Otto Maria Carpeaux e outros. Nesse momento, no ano de 1956, contava 40 anos de idade e tinha larga experiência jornalística (em jornais e revistas). $\mathrm{O}$ destaque da atividade precedente fica por conta das crônicas, posteriormente selecionadas em livro, que escreveu durante 12 anos na coluna "Sete Dias" de $O$ Cruzeiro, revista que pertencia ao grupo de Assis Chateaubriand. A saída da revista e a chegada ao Correio envolveu a atuação política do crítico maranhense contra o patrão: Chateaubriand quis repetir uma manobra política (chamada "Operação Paraíba”) para se tornar senador no Maranhão. Franklin de Oliveira articulou oposição e foi suplente do candidato eleito (Armando Serra de Meneses). Depois disso, Oliveira teve um período de forte atuação como crítico até 1960 , ano em que abandonou a capital para tornar-se secretário-geral do Conselho de Desenvolvimento do Rio Grande do Sul, no governo de Leonel Brizola. Tudo isso, além de estar entre os cem primeiros cassados pelo golpe de 1964, demonstra que Oliveira, assim como Álvaro Lins, sempre esteve dividido entre a crítica e a política. E, depois da cassação, voltaria a se dedicar novamente à crítica (NotícıA..., 1983, p. 141). ${ }^{6}$

\section{Os rodapés}

Para examinar o que Wilson Martins escreveu sobre Graciliano Ramos e Guimarães Rosa, é conveniente desconsiderar parcialmente a cronologia e abordar primeiro a totalidade dos rodapés dedicados ao segundo escritor. Isso porque o crítico manteria uma posição de equívoco e contrariedade entre o rodapé acerca de Sagarana, em agosto de 1946, e aquele sobre Estas estórias, em fevereiro de 1970. Equívoco e contrariedade revelavam uma tentativa de coerência concernente a considerações estabelecidas já no primeiro rodapé, reforçadas de maneira enfática após a publicação das obras de 1956 e, com poucas alterações, nos rodapés subsequentes. Ao ler os contos de estreia, em texto que não é possível colocar entre os mais apurados quanto ao teor críticoanalítico, Martins compreendia o escritor, sobretudo, como contista ("fracassaria no romance"), que apresentava estilo "original e próprio" e poder descritivo, acrescentando, porém, que a "própria riqueza fosforescente, barroca

5 "Matriculou-se na Faculdade de Direito do Maranhão. [...] Abandonou, porém, o curso jurídico, logo que se transferiu para o Rio de Janeiro" (NotíciA..., 1983, p. 141).

6 Ver também o site da Academia Brasileira de Letras. 
e um pouco pirotécnica prejudica exatamente aquela necessidade de sugestão que me parece a qualidade primordial e o recurso indispensável do ficcionista" (Martins, 1946, p. 4-5). Já em 1956, o autor de Pontos de vista era bastante minucioso, fazia indicações crítico-analíticas precisas; entretanto, isso não foi suficiente para atribuir o justo valor literário e para o acerto dos juízos, muitos dos quais, vale assinalar, coincidiam com os de Sérgio Milliet no primeiro rodapé sobre Sagarana. Os dois rodapés sobre Corpo de baile e Grande sertão: veredas eram arrasadores desde o título, Um novo Valdomiro Silveira: "O sr. João Guimarães Rosa é um 'caso' cômodo para a crítica: é desses autores que se classificam de uma vez por todas, que conserva, de livro para livro, exatamente as mesmas qualidades e exatamente os mesmos defeitos" (MARTins, 1956, p. 8). ${ }^{7}$

Assim, a "previsão" de fracasso no romance, de dez anos antes, teria sido confirmada. O crítico demonstrava sua necessidade de manter a linha de leitura através de citações do primeiro rodapé e da manutenção dos pontos principais. O escritor era mesmo um excelente contista. Detalhavam-se as razões para tal compreensão dentro das limitações de um maior entre os menores, sem dúvida, um novo Valdomiro Silveira.

O crítico de $O$ Estado de S. Paulo argumentava que havia problemas de linguagem, de psicologia dos personagens e de composição romanesca. Guimarães Rosa só saiu com saldo positivo no primeiro deles, pois se via apenas o personagem Riobaldo pelo lado de dentro e o "monólogo infinito" com “arquitetura por justaposição" era "solução técnica" artificial, "psicologicamente pouco verossímil” (MARTINs, 1956, p. 8). Tudo isso permitia concluir que a obra ficava em débito, "deveria ser um 'documento humano'”, toda a obra "se apoia exclusivamente no estilo" (MARTINS, 1956, p. 8).

Nos rodapés seguintes, discretamente, Martins ponderou, mas teimosamente, sem abrir mão de uma linha interpretativa estabelecida ainda em 1946. Ao abordar Primeiras estórias em conjunto com obras de outros escritores, não deixou de lhe dedicar comparativamente mais espaço. Aí, além de sentenciar que Grande sertão: veredas era o paroxismo da técnica do escritor, "o exemplo supremo", vislumbrava a literatura ideal em "Sequência" para, em seguida, arrematar que ainda tentava "chegar

7 Ver também Martins (1991a). 
à psicologia pela expressão" (MARTins, 1963, p. 2). ${ }^{8}$ Em fõe Guimarró, ao contestar filiações entre as obras e Mário de Andrade e James Joyce, o crítico valia-se de trechos de carta do escritor à sua orientanda Mary L. Daniel para reforçar sua linha, ${ }^{9}$ mas, ao mesmo tempo, reconhecia o estatuto que a obra adquiriu ao dizer que não se tratava mais de apontar "qualidades e defeitos" ("expressão consagrada" da crítica de rodapé), era preciso "estudar-lhe a arte de escritor" (MARTins, 1965, p. 2), ${ }^{10}$ ou seja, não estava mais em seu âmbito preferido de atuação, apesar da sua também condição de professor universitário. E mais: a leitura "só se pode fazer lentamente, com repetidos retornos e largas assimilações do que foi dito" (Martins, 1965, p. 2). E ainda: "ele é daqueles escritores que desorientam os críticos 'de segunda ordem'” (MARTins, 1965, p. 2).

Depois dessas ponderações, ainda na condição de crítico titular de $O$ Estado de S. Paulo, onde escreveria até o ano de 1974, nos dois últimos rodapés a respeito dos dois últimos novos livros, Tutaméia e Estas estórias, Wilson Martins não fez questão de muitas demonstrações críticoanalíticas. Foi pontual. Em Literaturnost', a breve discussão sobre prefácios e literariedade servia para dizer que, nesse quesito, Tutaméia era excelente, mais uma vez, "uma visão linguística do mundo que, em Guimarães Rosa, é mais sensível do que a sua visão do mundo através da literatura: para ele, a infelicidade não é o drama ou a tragédia do homem - 'é questão de prefixo"” (MARTins, 1968a, p. 4). ${ }^{11}$ Sobre Estas estórias, desenvolvia questões secundárias em abordagem ruim, mas propunha formulação sugestiva quanto às dificuldades que teve para a compreensão das obras nos seguintes termos:

Sua visão do homem é pitoresca, não há dúvida nenhuma, mas corrigida e negada pela visão trágica ou, pelo menos, dramática, do mundo: sua obra é, no fundo, uma tentativa de conciliação desses dois extremos, dessas duas aparentes incompatibilidades. É a visão do mundo que comanda o andamento da narrativa, mas é a visão do homem que conforma o estilo (MARTINS, 1970, p. 4). ${ }^{12}$

"Páramo" estaria próximo de um extremo (dramático), enquanto "Meu tio o Iauaretê", de outro (pitoresco). Entretanto, para não descuidar da coerência,

8 Ver também Martins (1991b).

9 Ver carta datada de 9 de fevereiro de 1965, Arquivo de Wilson Martins, Fundação Casa de Rui Barbosa, Rio de Janeiro.

1o Ver também Martins (1991d).

11 Ver também Martins (1991e).

12 Ver também Martins (1991f). 
insistentemente mantida desde a publicação de Sagarana, repunha o julgamento de serem mesmo os processos estilísticos "o seu atrativo mais saliente" (MARTINS, 1970, p. 4).

Já sobre Graciliano Ramos, o próprio Wilson Martins tomava "Graciliano Ramos, o Cristo e o Grande Inquisidor" (FIgura 1) como um dos seus "estudos mais trabalhados" (MARTins, 1953b, p. 5).

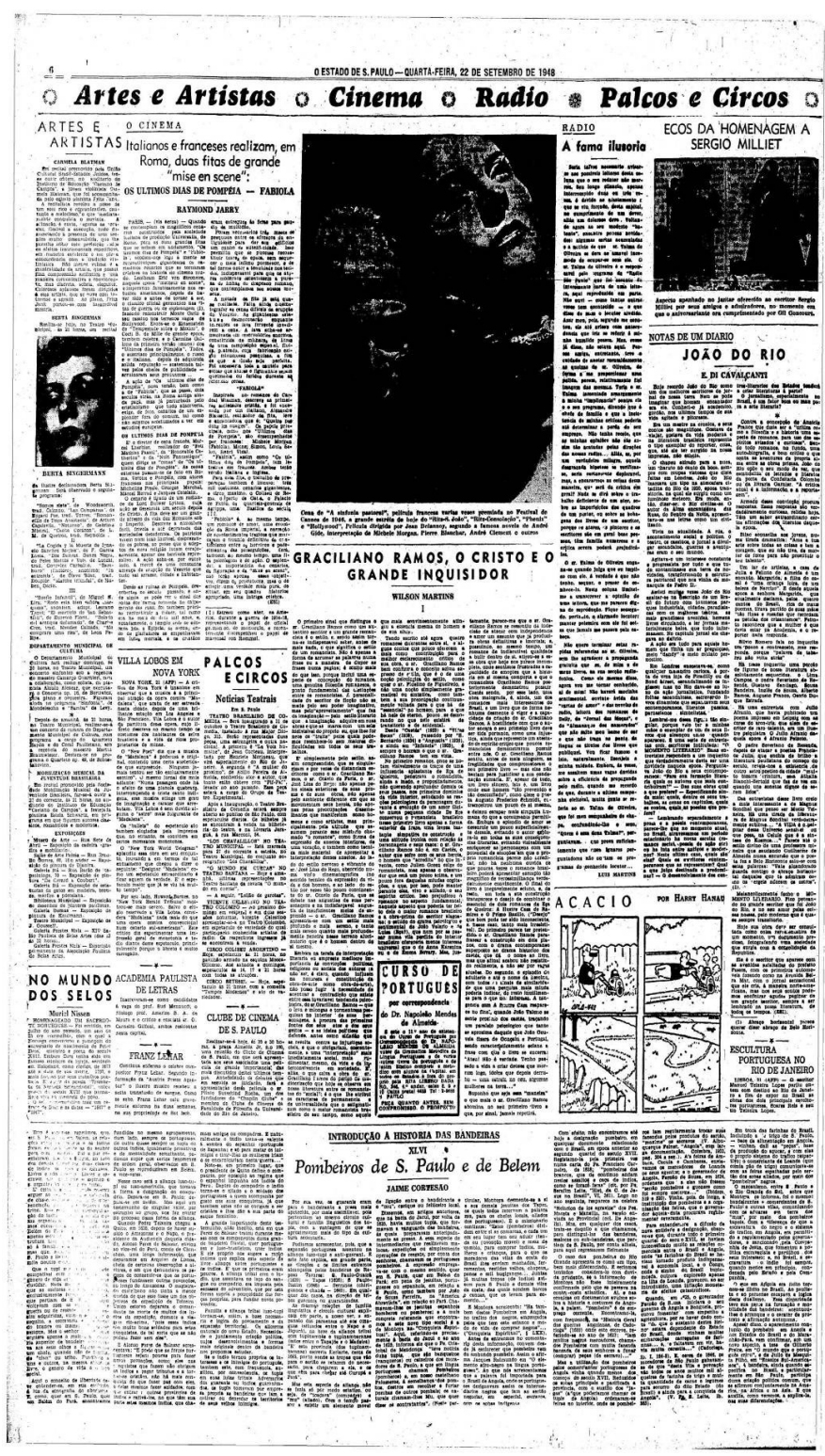

Figura 1 - Página de $O$ Estado de S. Paulo com a primeira parte de "Graciliano Ramos, o Cristo e o Grande Inquisidor". 
O crítico o elaborou depois dos estudos de Otto Maria Carpeaux (1943), ${ }^{13}$ Álvaro Lins (1947) e Antonio Candido (1945a; 1945b; 1945c; 1945d). Entretanto, conseguiu imprimir sua marca à leitura que rendeu texto ensaístico fora de suas características mais recorrentes de apontar "qualidades e defeitos". Embora ensaio, o texto também foi oferecido aos leitores de $O$ Estado de S. Paulo entre 22 e 25 de setembro do mesmo ano (Martins, 1948a; 1948b; 1948c). ${ }^{14}$ Mas, de fato, tratava-se de estudo em que Martins se eximia de demonstrações críticoanalíticas para retomar pontualmente aquilo que interessava à sustentação de sua linha interpretativa, a qual compreendia estilo em sentido psicológico "marca com um selo indivisível do próprio eu" (MArtins, 1978, p. 34) e apontava contradição entre tendência psicológica (longas pesquisas no interior dos personagens) e ideias políticas que o escritor defendia. Chegou mesmo ao ponto de identificar nas obras "inquietude verdadeiramente calvinista". Tais eram as vigas mestras da interpretação proposta, a qual se concentrou sobretudo ao discorrer sobre o romance Angústia, muito embora São Bernardo fosse considerado o melhor. Convém retomar os termos do crítico:

\footnotetext{
é também a indistinção moderna entre o Bem e o Mal, numa sociedade em que os valores se misturam de tal maneira que se repete a história do Cristo e do Grande Inquisidor. Impossível evitar Dostoievski quando se fala nas concepções morais do Sr. Graciliano Ramos: nas suas concepções morais vis-à-vis da sociedade. Seu olhar, assim, se dirige para mais longe do que o espetáculo imediato dos homens formigando e defendendo as suas reivindicações de classe (MARTins, 1978, p. 39).
}

Dessa forma, é possível estabelecer pontos de convergência entre Martins e Álvaro Lins. Sem entrar na discussão de realidade estática ou dinâmica, como fazia Lins, o autor de Pontos de vista aproximava desde o título as obras do escritor brasileiro e as do russo por meio do capítulo destacado e destacável de Os irmãos Karamazov. Tudo isso trazia água para o moinho de uma interpretação na qual se substancializava o ser humano "não depende das transformações exteriores nem do sistema de vida na sociedade circundante para ser o que é" (MArtins, 1978, p. 38) e, portanto, valorizava literariamente o autor de Angústia enquanto primordialmente "romancista psicológico", "o maior romancista brasileiro de seu tempo, como aquele que mais convincentemente atingiu a essência mesma do homem e de sua alma" (Martins, 1978, p. 38). Embora Martins concluísse

13 Esse é o ano da versão do ensaio em livro.

14 Ver também Martins (1978, p. 34-45). 
As obras de Graciliano Ramos e Guimarães Rosa nos Rodapés de Wilson Martins e Franklin de Oliveira

o parágrafo anteriormente citado com a constatação de que o problema humano era "muito mais ontológico que político", sua interpretação também não deixava de ser interessada e o lugar central atribuído à lenda do Grande Inquisidor não era meramente literário e ontológico. Certamente, o crítico pretendia fundamentar ontologicamente a discussão política, mas ela era, antes de tudo, política. E isso ficou evidente em estudo posterior, de 1951, propriamente político, intitulado Introdução à democracia brasileira. Depois de argumentar que a "democracia social não é um dado necessário na definição política de democracia” (MARTins, 1951, p. 27), Martins retomava a lenda fazendo a seguinte relação:

a questão constitui uma transposição, ou um exemplo ilustrativo, da "Lenda do Grande Inquisidor", de Dostoievski: trata-se de saber se pretendemos apenas aos bens materiais, ou se desejamos com igual empenho certas garantias de ordem espiritual, como a liberdade, por exemplo (Martins, 1951, p. 28-29).

Assim sendo, fazia-se a leitura de Graciliano Ramos de maneira que pode ser considerada a contrapelo. O próprio crítico dizia ser "estranho" encontrar "concepção católica do mundo" em "escritor comunista”, em duas classificações que, no tocante às obras, são questionáveis. E Martins salientava que Graciliano Ramos provavelmente não teria aprovado a linha interpretativa: "mas que fazer? Escrevo não para satisfazer os autores, ou suas famílias, mas tendo em vista uma ambição mais alta, que é a de testemunhar a vida literária do Brasil durante o ínfimo tempo que me for dado vivê-la" (MARTins, 1953b, p. 5).

Essa última passagem citada, de 1953, remetia à rusga entre Wilson Martins e Ricardo Ramos, filho do escritor já então falecido, quando da publicação de Memórias do cárcere. $\mathrm{O}$ crítico, atento, verificou que havia diferenças entre o texto publicado e o fac-símile reproduzido na mesma edição. Valeu-se disso para apontar alterações em livro póstumo e observar que "não merecem confiança”. Ricardo Ramos mandou nota de esclarecimento ao jornal O Estado de S. Paulo, informando que havia outras versões originais e acusava o crítico por conclusões apressadas (RAmos, 1953, p. 19). ${ }^{15}$ Os dois rodapés concernentes ao livro giraram em torno desse imbróglio, mas

15 Após o segundo rodapé de Martins, o jornal fez questão de encerrar a polêmica em pequena nota que se seguia imediatamente ao texto: "N. da R. - Com a publicação deste artigo o $O$ Estado de S. Paulo considera o incidente definitivamente encerrado, no que lhe diz respeito, uma vez que as duas partes tiveram a oportunidade de manifestar-se amplamente através das suas colunas". 
Martins também repunha sua interpretação da obra e do escritor: "O 'tom' inteiro do livro é profundamente anticomunista", "por uma religião, uma igreja, uma comunidade e uma ordem Graciliano Ramos se debateu a sua vida inteira, sem o saber" (MARTins, 1953a, p. 1). E tomava as Memórias como "a crítica mais feroz (e quão autorizada!) que se poderia fazer ao partido comunista brasileiro" (MArtins, 1953a, p. 1). Assim como dava primazia ao romancista enquanto "psicológico", Martins privilegiou o que havia de crítica ao partido e aos companheiros de partido em detrimento do relato das arbitrariedades e solidariedades inesperadas - entre, é certo, diversas outras questões do livro longo e sinuoso.

Em 1962, ao tratar de outros dois livros póstumos, Alexandre e outros heróis e Viventes das Alagoas, Martins realizava nova abordagem de conjunto sobre as obras para definir o lugar à parte que cabia a Graciliano Ramos na história da literatura brasileira e, ainda, depois de citar Carpeaux, alçá-lo ao plano da literatura universal. Os termos, então, eram de acomodação do escritor com os governos de 1930 e depois (isso pelos cargos que ocupou em 1930 e de 1933 a 1936). Entretanto, por outro lado, caracterizava-o como o lobo da estepe, "um marginal da literatura em moda, assim como foi um marginal do sistema político dominante e, de forma sensível, um marginal dos grupos sociais em que viveu" (Martins, 1962, p. 2). ${ }^{16}$ Quanto a Viagem, salientava, com pertinência, que o viajante sufocava o espírito crítico para acreditar no que lhe contavam e mostravam. A essa altura, no ano de 1962, Martins argumentava no sentido de vislumbrar o que o escritor seria "no fundo", novamente a contrapelo das obras, tomando-as como impelidas pelo meio. A revolução dele seria alencariana, uma revolução romântica: "a sua vida perturbada e perturbadora poderia ter sido o grande romance que estava nas suas possibilidades e que ele quase escreveu com as Memórias do cárcere" (MARTins, 1962, p. 2). Dessa forma, embora de maneira menos radical e com melhor fundamentação críticoanalítica, as leituras que Martins fazia de Graciliano Ramos eram, assim como aquelas de Guimarães Rosa, pautadas por equívocos.

Tais equívocos, entretanto, passaram por ponderações no último escrito de Wilson Martins que, pelo período em que foi primeiramente publicado, aqui nos interessa. Trata-se de Structural perspectivism in Guimarães Rosa, de 1973

16 Ver também Martins (1991b, p. 106). 
As obras de Graciliano Ramos e Guimarães Rosa NOS RODAPÉS DE Wilson MARTINS E FrankLin de OliveIRA

(Figura 2), posterior a "Gênio e talento" (Martins, 1970, p. 4). ${ }^{17}$ Nesse texto, que não circulou em português, Martins se aproximava de leituras de Candido e Cavalcanti Proença, ${ }^{18}$ procurando equilibrar o regional e o universal e, ainda, fazia contraste com Dom Quixote - em vez de "linguistic perspectivism" (SPITZER) haveria no romance brasileiro "structural perspectivism" ${ }^{19}$ Um escrito, portanto, que destoava dos outros em mais de um aspecto - e com ele, nesse ano de 1973, encerram as investigações que realizamos quanto aos escritos que Wilson Martins dedicou aos dois escritores brasileiros.

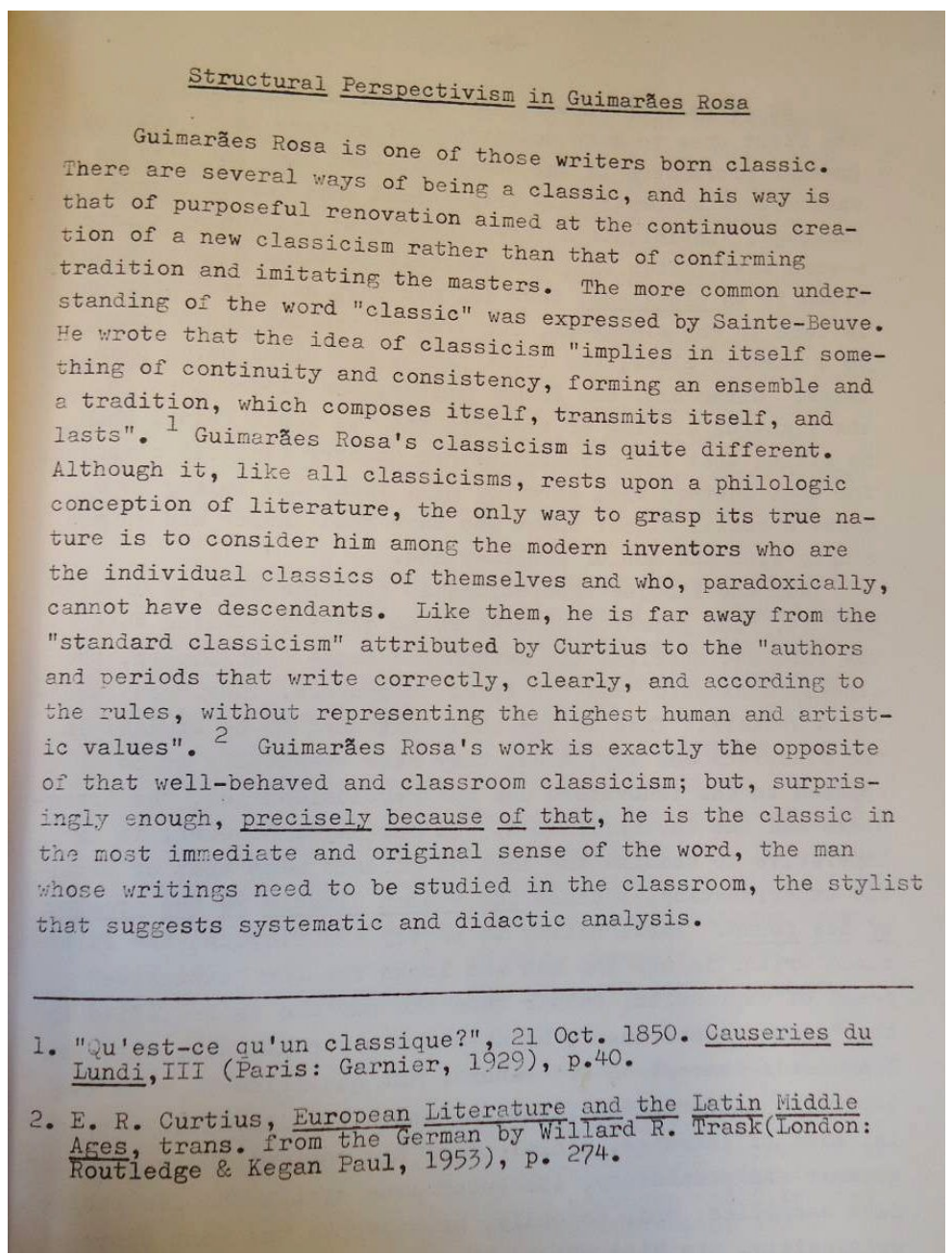

Figura 2 - Primeira página de Structural perspectivism in Guimarães Rosa

17 Ver também Martins (1991e).

18 Para mais detalhes sobre a relação com esses autores, ver Macedo (2015).

19 O texto consta da biblioteca da Universidade de Nova York (NYU) como parte da série "Occasional Papers" e no livro The Brazilian Novel (Martins, 1976). 
O crítico do Correio da Manhã, Franklin de Oliveira, foi um daqueles que, ocupando a coluna Livros na mesa (FIgURA 3), procurou "preencher, na medida do possível, a constante falha que vem sendo apontada em nosso ambiente literário: a escassez de uma crítica especializada" (Livros..., 1956, p. 8). E em afirmação que deve ser entendida como contraponto a Afrânio Coutinho, Oliveira dizia que, embora "indispensável”, a crítica formalista não bastava, já que o "estético" era apenas um dos elementos:

A verdadeira crítica é uma espécie de nova 'análise combinatória' - para a valorização da obra literária utiliza-se de todas as estratégias, tão certa está de que, no contexto literário, manifestam-se fatos estéticos, éticos, religiosos, filosóficos, sociais (OLIVEIRA, 1957, p. 1; 1965a, p. 15-16).

A “análise combinatória” do crítico, entretanto, revelava-se, na prática, confusa e dispersa. É o que evidencia a leitura das coletâneas de A fantasia exata e Viola d'amore, as quais não possuíam abordagens diretas sobre Graciliano Ramos e Guimarães Rosa.

Um conjunto de escritos, entre eles rodapés publicados em Livros na mesa, foram reunidos e, com poucas alterações, mesclaram-se a páginas inéditas para compor o capítulo sobre Guimarães Rosa em volume de A literatura no Brasil, sob direção de Afrânio Coutinho. Os rodapés Corpo de baile (de 1956) e As epígrafes (de 1958, sobre as epígrafes de Sagarana) juntaram-se a outros dois textos, não mais na condição de rodapé, Revolução roseana (de 1967) e A egrégia fidelidade (de 1968). ${ }^{20}$ Assim, durante um período de mais de dez anos, entrecortado pela atuação política, Franklin de Oliveira elaborou quase 50 páginas sobre o escritor, ao qual se dirigia como amigo, e a obra. De fato, além do testemunho do crítico nos textos em questão e em outros, a dedicatória de Grande louvação pastoril à filha de Oliveira confirma a relação de proximidade com Guimarães Rosa. ${ }^{21}$ Isso deve ser assinalado porque interferia na leitura, um tanto passional. A amizade certamente era uma das razões para a defesa contra acusações de que o escritor seria

${ }_{20}$ Os rodapés foram publicados nas seguintes datas: "Corpo de Baile”, em 12 de maio de 1956; e "As epígrafes", em 25 de outubro de 1958. Os outros dois textos, "Revolução roseana" e "A egrégia fidelidade", não mais em rodapé, foram publicado em 25 de novembro de 1967 e 8 de dezembro de 1968, respectivamente.

${ }^{21}$ Trata-se de poema escrito por ocasião do nascimento de Lygia Maria, filha de Franklin de Oliveira, em março de 1953 (cf. RosA, 2009, p. 1.034-1.043). Escritor e crítico eram amigos, pelo menos desde 1946, ano que consta na dedicatória de Sagarana (" $7 / \mathrm{x} / 46$ "). Ver Biblioteca Pessoal de Franklin de Oliveira, Biblioteca Rodolfo Garcia, Academia Brasileira de Letras, Rio de Janeiro. 
apolítico e, ainda, para colocá-lo em consonância com suas próprias convicções políticas (as de Oliveira), e tentar situá-lo no campo da esquerda, desvendando nas obras um "marxista in natura" em sua "verdade mais subterrânea" (OliveIRA, 1967, p. 1; 1991, p. 185).

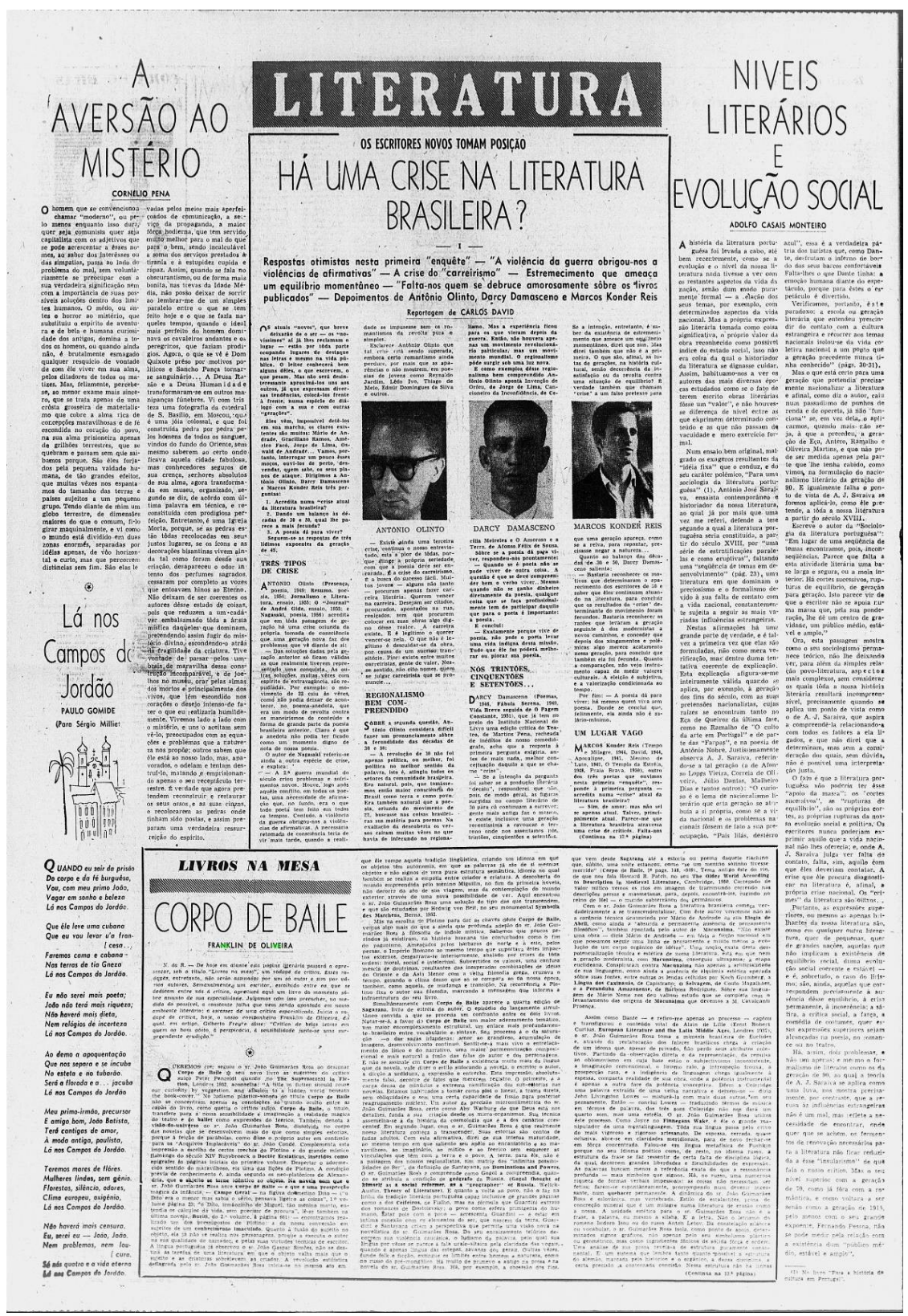

Figura 3 - Página com o primeiro rodapé de Franklin de Oliveira, sobre Corpo de baile Obs.: em nota, o jornal apresentava e qualificava Oliveira logo após o nome do crítico. 
No que se referia ao autor de Sagarana, essa era uma das marcas importantes da crítica de Franklin de Oliveira, o que lhe proporcionava dificuldades. Entretanto, em relação a esse escritor e a outros, havia mais dificuldades. Primordialmente jornalista, o crítico tentava mobilizar de maneira excessiva um sem número de referências, ora especificando-as em notas, ora apenas colocando o nome do autor entre parênteses, ora, ainda, fazendo citações sem nenhuma indicação. Com tais procedimentos, Oliveira muito provavelmente pretendia qualificar os próprios textos ao demonstrar fundamentação e equiparar-se à nova leva de críticos, alguns dos quais já estavam em atividade desde a década anterior - Oliveira chegou a se referir a eles, ou a parte deles, como "crítica bem penteada" após propor pontos de contato entre Górki e Guimarães Rosa em abordagem sobre o primeiro escritor: "Sei que esta afirmativa vai arrepiar a crítica bem penteada. Que ela se dane" (Oliveira, 1978, p. 192). Tudo isso, porém, não impedia que os textos carecessem de apuro crítico-analíticos, um dos pontos fortes dos melhores críticos de rodapé. Assim, a falta desse apuro, em associação com referências e expressões estrangeiras excessivas contribuíram para distanciá-lo dos melhores rodapés.

Apesar desses problemas, Oliveira foi capaz de apontar diversas questões relevantes e mapear temas basilares das obras do escritor mineiro. As obras romperiam dialeticamente (conservar e superar) com a tradição de "livros vingadores" (Os sertões e O Ateneu); Guimarães Rosa seria contrairracionalista, Joyce, irracionalista - as obras daquele seriam "um ato de busca da santidade do homem" e com elas surgiram os primeiros heróis resolutos da nossa literatura, o ideal que as informa seria o do "homem harmonioso"; Rosa buscava nas religiões a "partitura" para ler os mistérios do universo; o lugar da esteticidade: para solucionar o problema político "é necessário caminhar através do estético, pois é pela beleza que se vai à liberdade" (citação de SCHILler); na estória do burrinho pedrês, animal cujos sentimentos eram aproximados aos de certas cosmovisões religiosas, da ataraxia dos estoicos e do bem ver no escuro (forças do inconsciente), desde a epígrafe já estava dado que ele tinha o seu papel, o seu destino: "Vai cumpri-lo - rodar no mutirão"; em Corpo de baile, as palavras de Plotino e Ruysbroeck remeteriam ao despertar do "adormecido sentido do maravilhoso" em "contos de fadas adultos"; não seria certo aproximar Riobaldo do mito cervantino e, sim, de Fausto e Don Juan; propunha a identificação de três Riobaldos: o jagunço, o fáustico, o místico, 
e de três tipos de amor: Nhorinhá, Otacília, Diadorim; indicava o significado etimológico de Riobaldo: rio falho, infecundo; estabelecia paralelo entre personagens de Corpo de baile e de grande sertão: veredas (exemplo: o "tema de Don Juan insinua-se na figura de Pedro Orósio"); abordava as relações entre Riobaldo e Diadorim (este seria, na verdade, o "formidável personagem vertical"); interpretava o sertão como "subconsciente"; falava da importância do menino nas obras e interpretava isso como posição política ("pressuposto de defesa social da criança"); destacava a dimensão política dos personagens Santos Óleos (descobria pecado em todas as coisas) e Coletor (fazia cálculos alucinatórios de fortuna); fazia comparações com Dostoiévski e dizia que a tese central em Grande sertão: veredas era o predomínio da "graça" sobre a "lei", "preconizado como solução poético-feérica para o problema do destino" (Oliveira, 1970, p. 402-449). ${ }^{22}$

Além disso, o crítico defendia as teses de que os personagens seriam "seres ideais" em "situações concretas" e de que havia uma "filosofia da alegria":

\begin{abstract}
Há uma passagem em Tutaméia, em que se lê: “... queria apenas os arquétipos, platonizava”. Aqui está a chave dos motivos que levaram João Guimarães Rosa, sobretudo a partir de Primeiras estórias, a não lidar simplesmente com personagens segundo a acepção vulgar deste termo, mas sobretudo com seres ideais inseridos em situações concretas. [...] Tirante a coragem para apontarmos nessa beirada, ou perlongar-lhe a orla, resta outra alternativa: a da filosofia da alegria, que Guimarães Rosa também propõe como solução poético-feérica para o problema do destino humano (OliveirA, 197o, p. 437).
\end{abstract}

Apesar de confusa e dispersa, a crítica de Franklin de Oliveira era, realmente, combinatória. Nisso, é possível estabelecer profundo contraponto com a linha interpretativa de Wilson Martins e, ainda, com as obras de Graciliano Ramos. Não se tratava de mera literariedade, como entendia Martins - nem estrito brasileirismo, como indicava Sérgio Milliet. O formalismo era incorporado à leitura no intento de articular as várias faces do idealismo com a negativa ante a uniformização do mundo moderno: "A revolução estilística rosiana reveste-se, também, do sentido de protesto contra a sociedade tecnológica", pois a "civilização unidimensional, que suprime o principium individuationes, reduziu a linguagem a uma rasa, reles seriação de clichês, fórmulas feitas - fechou o universo da alocução,

22 As aspas em graça e lei são do próprio crítico. 
ao transformá-lo em puro aparato de estereotipias"; portanto, a "arte de Rosa recusa a civilização que gerou a antilinguagem". A escolha de um universo primitivo, antiurbano, teria sido consciente, pois "no sertão não se registram a impessoalidade da vida, nem a perda do mistério das coisas" (OliveirA, 1970, p. 441-443).

A linguagem e a relação com o mundo moderno também seriam tema de artigo sobre Graciliano Ramos em 1975 (Oliveira, 1975, p. 29), por ocasião de reedição das obras completas do escritor. Publicado originalmente em O Globo, o texto integra o volume da Fortuna crítica, organizado por Sônia Brayner (OliveirA, 1978, p. 310-316), o que certamente garantiu mais leitores para Franklin de Oliveira. No jornal, embora extemporâneo, o artigo tinha a motivação que dava ensejo aos rodapés. E num escrito sucinto, o crítico evitou a confusão e dispersão costumeiras, pontualmente questionou leituras psicologistas e sociológicas, colocou como central o papel que cabe, na obra, à alienação, e, ainda, propôs que a questão do amor e sua desnaturação seriam as razões pelas quais o escritor interessaria às novas gerações. Assim, ao contrário dos "seres ideais" e da "filosofia da alegria" de Guimarães Rosa, a via do embate com a alienação em Graciliano Ramos realizava-se através de "concisa prosa" que nos submete a "uma tensão contínua, que nos enriquece, na medida em que nos fecha os cômodos caminhos do conformismo" (OliveIrA, 1978, p. 310-316). O romancista "aponta concretamente as causas reais do sofrimento de sua gente e de sua terra", e como Tchekov e Gorki, Graciliano Ramos seria o narrador de "um imenso país imóvel" (Oliveira, 1978, p. 310-316). Uma das causas reais do sofrimento, para o crítico, passava pelo tema do amor, o qual não seria incólume à situação histórica coisificante. Há "desencontro da linguagem" (aspas de Oliveira) e os personagens são "pessoas insuladas": "O selvagem desencontro em que suas vidas se estilhaçam resulta de uma vigência social que desnatura o amor" (Oliveira, 1978, p. 310-316).

Franklin de Oliveira tentava, portanto, esmiuçar os temas centrais e o estilo (agora sob a designação de "linguagem") específicos de Guimarães Rosa e Graciliano Ramos sem, ao mesmo tempo, descuidar da realidade moderna em âmbito global e comparar os dois escritores brasileiros preferencialmente a russos - em outro texto, de 1968, o crítico voltava reforçar esse ponto ao falar em "muitos traços do russismo roseano" (Oliveira, 1978, p. 193). A “análise combinatória" abarcava muitos 
elementos, mas, além de ser expressa de modo confuso e disperso, deixava entrever que os agrupamentos eram realizados inconsistentemente.

Voltando a Wilson Martins, podemos afirmar que ele tinha pontos de convergência com Lins e Milliet ${ }^{23}$ em escritos que privilegiavam, como ficou mais que evidente, a literatura de Graciliano Ramos a partir de leitura a contrapelo. Fundamentavam tal postura crítica: a também valorização, tal como Milliet, de características de estilo próximas ao estilo modernista (“'modernista malgrado seu', o modernista de má vontade”); a também capacidade, tal como Lins, de identificação e compreensão de uma composition desserrée (que remetia a Thibaudet) ${ }^{24}$ e estava vinculada à substancialização humana através da psicologia ("arrojo de mexer no que o homem tem de mais íntimo e de mais misterioso", "não depende das transformações exteriores nem do sistema de vida na sociedade circundante para ser o que é"); a problemática articulação ontológico-moral-político que se sucedia à mencionada substancialização do humano ("estranho que as ideias desse escritor comunista se venham encontrar tão visivelmente com a concepção católica do mundo", "os valores se misturam de tal maneira que se repete a história do Cristo e do Grande Inquisidor" - o que certamente remetia à posição democrático-liberal do crítico, embora complicasse a compreensão por causa das menções a calvinismo e catolicismo). O estilo, tal como inicialmente em Milliet, também constituiu barreira para a abordagem de Guimarães Rosa. Martins apontava desde o início a "riqueza fosforescente, barroca e um pouco pirotécnica" e insistiu nesse ponto até o fim, livro após livro, julgando serem os processos estilísticos "o atrativo mais saliente". Além disso, assim como no caso de Graciliano Ramos, em que empreendeu leitura a contrapelo, o crítico parecia tentar o mesmo com Guimarães Rosa, mas de maneira ainda mais radical, é o que é possível deduzir da valorização que fazia de estórias como "Sequência" e "Páramo" (MArtins, 1948a; 1948b; 1948c;1953a; 1953b; 1962).

No contexto dos anos 1940, Wilson Martins era um dos novos críticos de rodapé e, a partir de então, como vimos, leu e releu obras de Graciliano Ramos e Guimarães Rosa. Entretanto, Martins foi um novo que se definiu ao passar

23 Para mais detalhes sobre os rodapés desses autores, ver Macedo (2015).

${ }^{24}$ Para mais detalhes, ver Macedo (2015). 
dos anos pela extemporaneidade, em vários sentidos. ${ }^{25}$ Enquanto Álvaro Lins problematizava o "ainda" de discussões teóricas de Thibaudet para a leitura de prosa de ficção no final de 1946, o autor de Pontos de Vista considerava-o, no final de sua vida, ainda, o "meu mestre teórico na literatura francesa", "penso que eu sou o último crítico formado nessa tradição francesa". ${ }^{26}$

Apesar de ter sido autor de diversas obras ${ }^{27}$ e professor universitário durante quatro décadas, na Universidade Federal do Paraná e na Universidade de Nova York (New York University - NYU), Martins afirmava ser "leitor profissional". O magistério foi "um complemento disso tudo", mesmo como professor, desejava ser um crítico que desperta "nos estudantes o espírito crítico e o amor à leitura”. ${ }^{28}$ Consequência disso foi a fidelidade ao rodapé, mantida até o fim. ${ }^{29} \mathrm{E}$ um desdém por teoria e método, ao qual não se furtou a aludir: houve várias teorias, "o que prova que nenhuma delas era 'a teoria”, "a teoria não é mais importante que a matéria", "eu proponho esta ideia, de que nenhum método é bom e todos são bons dependendo da aplicação que se queira fazer" (MARTins, 2001, p. 16).

Várias pesquisas reforçaram essa autoanálise de Wilson Martins como crítico preso ao rodapé. ${ }^{30}$ Para mencionar, primeiramente, um testemunho, encontramos um artigo de Paulo Leminski sobre as "grandezas e limites" do crítico: a coluna dele era uma "verdadeira universidade aberta"; " $\mathrm{Li}$ o, religiosamente, durante meus anos mais verdes, anos de formação e de definição, do gosto e da sensibilidade"; "Wilson Martins é da época em

${ }_{25}$ Flora Süssekind, que não foi a única a entrar em rota de colisão com Martins, criticou essa extemporaneidade após a morte dele em texto intitulado "A crítica como papel de bala" (SüsSEKIND, 2010). Entretanto, mesmo extemporâneos, o efeito dos rodapés podia ser positivamente imprevisível, como deixa claro o depoimento de Moacyr Scliar. O escritor, satisfeito com uma crítica favorável, guardava-a no bolso, retirando-a de tempos em tempos para reler. Ver Wilson Martins: a consciência da crítica, documentário de Douglas Machado (2010).

26 As citações são provenientes das reflexões do crítico em Martins (2001, p. 15-18). Para uma discussão mais detalhada dessa questão, ver Macedo (2015).

${ }^{27}$ A extensa bibliografia inclui as obras já citadas e ainda outras: Intepretações (1946); Introdução à democracia brasileira (1951); Imagens da França (1952); A crítica literária no Brasil (1952); Um Brasil diferente (1955); A palavra escrita (1957); O modernismo (1965); Teatro brasileiro contemporâneo, em colaboração com Seymour Menton (1966); História da inteligência brasileira (1979).

28 Ver também as reflexões em Martins (2001, p. 9).

29 Um exemplo bastante revelador dessa fidelidade ao rodapé e à sua linguagem acessível ao público médio de jornal foi o fato de Martins ter simplesmente traduzido e publicado o capítulo sobre Thibaudet, que compunha sua tese. Ver Wilson Martins (1952; 1953c; 1953d; 1953e).

30 Analisamos livros e documentos diversos relacionados às atividades de Wilson Martins nos seguintes locais: Universidade Estadual de Ponta Grossa, Biblioteca Pública do Paraná, Fundação Casa de Rui Barbosa, Universidade de Nova York e Universidade de Princeton. 
que dava para ler crítica literária, aqueles tempos em que o saber profundo e a formulação precisa coincidiam com a cursividade do jornalismo e o prazer e proveito do leitor comum." O poeta, entretanto, não deixava de contestá-lo: "Falta loucura à inteligência de Wilson Martins. Sua visão da criação literária é acadêmica e conservadora" (LEMINSKI, 1986).

Do próprio crítico, foram um tanto restritos os exemplos de expansão da atividade mais especificamente universitária, entre eles, certamente podemos incluir: a condução de um seminário sobre Grande sertão: veredas na Universidade de Wisconsin (antes de se transferir para a NYU); ${ }^{31}$ o estudo de Mary Lou Daniel (1968) proveniente desse seminário, que contou com a orientação de Martins; as aulas sobre história e autores da literatura brasileira e Guimarães Rosa na NYU. Essa disciplina sobre o escritor mineiro, ${ }^{32}$ devido à proximidade de datas, certamente levou o crítico a elaborar um estudo que, na linha do que argumentamos, era mais um dos poucos exemplos de atividade propriamente universitária - como vimos, "Structural perspectivism in Guimarães Rosa", último escrito de Wilson Martins levado em consideração, era de 1973.

E quanto a Franklin de Oliveira? Enquanto Wilson Martins manteve-se convicta e deliberadamente dentro dos limites e limitações da crítica de rodapé, podendo, em certo sentido, ser considerado um sucessor de Álvaro Lins, e, ainda, enquanto o mesmo Martins poderia ter empreendido mais estudos em moldes universitários, a iniciativa de extrapolar os moldes do rodapé e tentar aproximação com os procedimentos de um texto universitário foi o intento de Oliveira. O autor de Viola d'amore, que não possuía nenhum tipo de formação específica em Letras, embora tenha atuado já nos anos 1950, leu atentamente Teoria da literatura, de Wellek e Warren, mas não estava em condições de assimilá-lo satisfatoriamente. Além disso, em mais um passo em falso, remetia sem aprofundamento a formulações de um crítico chamado Vladimir Ermilov: um "segundo formalismo" (aspas dele), "no qual se dá o enlace da análise estrutural com a análise sociológica" ${ }^{33}$ Assim, a "análise combinatória” e as

${ }^{31}$ Ver o que o crítico registra em Martins (1968).

32 Constava, pela primeira vez, na lista de disciplinas para "Brazilian Literature": "[G87.27乃 Guimarães RosA. To be given in 1972-1973.]”. Ver NYU (1971, p. 247).

33 A citação provém de Oliveira (1965b, p. 187). Constava na biblioteca pessoal de Franklin de Oliveira o exemplar de Wellek e Warren, com muitos sublinhados e anotações, em tradução espanhola, da Editorial Gredos, de Madri, publicado em 1953. Por outro lado, não havia nenhum exemplar do livro de Ermilov. Ver Biblioteca Pessoal de Franklin de Oliveira, Biblioteca Rodolfo Garcia, Academia Brasileira de Letra, Rio de Janeiro. 
tentativas de equiparação com críticos de formação universitária malograram. E o resultado foram rodapés confusos e dispersos que estavam abaixo do teor crítico-analítico dos melhores críticos de jornal. Tratava-se de um cruzamento de referências descompassado e tenso. Nisso, entretanto, valorizou devotadamente as obras de Guimarães Rosa em escritos nos quais podemos distinguir: transposição da barreira do estilo, além de entendê-lo não apenas no âmbito brasileiro como protesto ante a uniformização tecnológica ("reagiu contra a rude manifestação repressiva que nivela a bela arte de escrever ao tique-taque telegráfico"); ênfase no mapeamento de questões primordialmente éticas, religiosas, filosóficas e sociais, portanto, deixando em segundo plano o estético (nisso, o importante era a tese de que o escritor lida sobretudo com "seres ideais inseridos em situações concretas"); articulação a contrapelo do dito mapeamento com o marxismo ("marxista in natura" em sua "verdade mais subterrânea" - o que certamente remetia a uma iniciativa de amigo e à posição esquerdista do crítico) (Oliveira, 1970).

Digno ainda de menção, apesar de entrar já pelo terreno da recepção em língua inglesa, tal como acabou ocorrendo com o ensaio não traduzido para o português de Wilson Martins, é o fato de Franklin de Oliveira ter colaborado para a recepção internacional de Sagarana, pois seu rodapé sobre as epígrafes da obra foi transformado na introdução à edição norte-americana, com tradução de Harriet de Onís (OliveIRA, 1966).

Os rodapés de Wilson Martins e Franklin de Oliveira apresentavam, portanto, vias de leitura bastante divergentes ao tratar de obras dos mesmos dois escritores, proporcionando relevantes discussões para a crítica e para o público. Além das interferências decisivas de posições políticoideológicas, como ficou claro, é preciso também levar em conta a atitude dos dois ante a transformação pela qual passava a crítica literária brasileira. Esse tema surgiu aqui de passagem, mas já é assunto para outra abordagem.

\section{Referências}

Candido, Antonio. Graciliano Ramos - i. Diário de São Paulo, São Paulo, p. 4, 4 out. 1945a.

CAndido, Antonio. Graciliano Ramos - II. Diário de São Paulo, São Paulo, p. 4, 11 out. 1945b.

CAndido, Antonio. Graciliano Ramos - iII. Diário de São Paulo, São Paulo, p. 4, 18 out. 1945c.

CAndido, Antonio. Graciliano Ramos - IV. Diário de São Paulo, São Paulo, p. 4, 25 out. 1945d.

Carpeaux, Otto Maria. Visão de Graciliano Ramos. In: Carpeaux, Otto Maria. Origens e fins. Rio de Janeiro: CEB, 1943, p. 339-351. 
As obras de Graciliano Ramos e Guimarães Rosa NOS RODAPÉS DE Wilson MARTins e FrankLin de Oliveira

Daniel, Mary L. João Guimarães Rosa: travessia literária. Rio de Janeiro: J. Olympio, 1968.

Leminski, Paulo. Wilson Martins: grandezas e limites. Gazeta do Povo, Curitiba, 22 ago. 1986. Artigo consultado em pasta de recortes da Biblioteca Pública do Paraná.

Lins, Álvaro. Visão geral de um ficcionista. Correio da Manhã, Rio de Janeiro, p. 2, 26 jun. 1947. Lins, Alvaro. A técnica do romance em Marcel Proust. Rio de Janeiro: J. Olympio, 1956.

Livros na mesa. Correio da Manhã, Rio de Janeiro, 12 maio 1956, p. 8.

MAcedo, André Barbosa de. Entre Graciliano Ramos e Guimarães Rosa: condições de recepção, leituras da crítica, questão de método. Tese (Doutorado em Literatura Brasileira) Universidade de São Paulo, São Paulo, 2015.

Machado, Douglas. Wilson Martins: a consciência crítica. Teresina: Trincafilmes, 2012. DVD.

Martins, Wilson. Sagarana. O Estado de S. Paulo, São Paulo, 29 ago. 1946, p. 4-5.

Martins, Wilson. Graciliano Ramos, o Cristo e o Grande Inquisidor. O Estado de S. Paulo, São Paulo, p. 6, 22 set. 1948a.

Martins, Wilson. Graciliano Ramos, o Cristo e o Grande Inquisidor. O Estado de S. Paulo, São Paulo, p. 6, 23 set. 1948b.

Martins, Wilson. Graciliano Ramos, o Cristo e o Grande Inquisidor. O Estado de S. Paulo, São Paulo, p. 6, 25 set. 1948 c.

Martins, Wilson. Introdução à democracia brasileira. Porto Alegre: Globo, 1951.

MARTINS, Wilson. Les théories critiques dans l'histoire de la littérature française. Curitiba: [S.n.], 1952.

Martins, Wilson. As memórias de Graciliano Ramos. O Estado de S. Paulo, Caderno "Literatura e Arte”, São Paulo, p. 1, 6 dez. 1953a.

Martins, Wilson. Ainda as memórias de Graciliano Ramos. O Estado de S. Paulo, São Paulo, p. 5, 25 dez. 1953b.

Martins, Wilson. O vinhateiro na sua vinha. O Estado de S. Paulo, São Paulo, 4 out. 1953c.

Martins, Wilson. Crítica e espírito filosófico. O Estado de S. Paulo, São Paulo, 11 out. 1953d.

Martins, Wilson. Crítica criadora. O Estado de S. Paulo, São Paulo, 18 out. 1953e.

Martins, Wilson. Um novo Valdomiro Silveira. O Estado de S. Paulo, São Paulo, p. 8, 23 e 30 ago 1956.

Martins, Wilson. O velho Graça. O Estado de S. Paulo, Suplemento Literário, São Paulo, p. 2, 2 jun. 1962.

Martins, Wilson. Caminhos da ficção-II. O Estado de S. Paulo, Suplemento Literário, São Paulo, p. 2, 26 jan. 1963.

Martins, Wilson. Jõe Guimarró. O Estado de S. Paulo, Suplemento Literário, São Paulo, p. 2, 8 maio 1965.

Martins, Wilson. Literaturnost'. O Estado de S. Paulo, Suplemento Literário, São Paulo, p. 4, 13 jan. 1968a.

MArtins, Wilson. Guimarães Rosa na sala de aula. In: DAniel, Mary L. João Guimarães Rosa: travessia literária. Rio de Janeiro: J. Olympio, 1968b, p. xi-xxxvii. 
Martins, Wilson. Gênio e talento. O Estado de S. Paulo, Suplemento Literário, São Paulo, p. 4, 21 fev. 1970.

Martins, Wilson. Structural perspectivism in Guimarães Rosa. New York: New York University, 1973. (Occasional Papers, n. 3).

MArtins, Wilson. Structural perspectivism in Guimarães Rosa. In: MARTINs, Heitor (org.). The brazilian novel. Bloomington: Indiana University Publications, 1976, p. 59-76.

Martins, Wilson. Graciliano Ramos, o Cristo e o Grande Inquisidor. In: Brayner, Sônia (Org.). Graciliano Ramos. 2. ed. Rio de Janeiro: Civilização Brasileira, 1978, p. 34-45.

Martins, Wilson. Um novo Valdomiro Silveira. In: Martins, Wilson. Pontos de vista. São Paulo: T. A. Queiroz, 1991a, v. 2.

Martins, Wilson. O velho Graça. In: Martins, Wilson. Pontos de vista. São Paulo: T. A. Queiroz, 1991b, v. 5, p. 106.

Martins, Wilson. Caminhos da ficção. In: Martins, Wilson. Pontos de vista. São Paulo: T. A. Queiroz, 1991c, v. 5.

Martins, Wilson. Jõe Guimarró. In: Martins, Wilson. Pontos de vista. São Paulo: T. A. Queiroz, 1991d, v. 6.

Martins, Wilson. Literaturnost'. In: Martins, Wilson. Pontos de vista. São Paulo: T. A. Queiroz, 1991e, v. 8.

Martins, Wilson. Gênio e talento. In: Martins, Wilson. Pontos de vista. São Paulo: T. A. Queiroz, 1991f, v. 8.

Martins, Wilson. O crítico por ele mesmo. In: Seffrin, André (Org.). Mestre da crítica. Curitiba: Imprensa Oficial do Paraná; Rio de Janeiro: Topbooks, 2001, p. 7-18.

NYU - NEW YORK UNIVERsity. New York University Bulletin: Graduate School of Arts and Science. Announcement 1970-1971. New York, 1970.

NOTícia sobre o autor. In: Oliveira, Franklin. Euclydes, a espada e a letra: florianistas e castilhistas no massacre de Canudos, Comte e outras influências reacionárias, as antecipações do autor de Os sertões. Rio de Janeiro: Paz e Terra, 1983, p. 141.

Oliveira, Franklin. Corpo de baile. Correio da Manhã, Rio de Janeiro, p. 8, 12, 12 maio 1956.

Oliveira, Franklin. De um certo modo, a crítica é a estética da leitura. Entrevista. Fornal do Brasil, Suplemento Dominical, p. 1, 26 maio 1957.

Oliveira, Franklin. As epígrafes. Correio da Manhã, Rio de Janeiro, p. 8, 25 out. 1958.

Oliveira, Franklin. Quase um diálogo. Quase um prefácio. In: Oliveira, Franklin. Viola d'amore. Rio de Janeiro: Edições do Val, 1965a, p. 15-16.

Oliveira, Franklin. A fortuna do formalismo. In: Oliveira, Franklin. Viola d'amore. Rio de Janeiro: Edições do Val, 1965b.

Oliveira, Franklin. Introduction: the epigraphs in Sagarana. In: RosA, João Guimarães. Sagarana. New York: Alfred A. Knopf, 1966, p. vii-xiv.

OliveirA, Franklin. Revolução roseana. Correio da Manhã, Rio de Janeiro, Quarto Caderno, p. 1, 25 nov. 1967.

Oliveira, Franklin. A egrégia fidelidade. Correio da Manhã, Rio de Janeiro, Quarto Caderno, p. 3, 8 dez. 1968. 
Oliveira, Franklin. Guimarães Rosa In: Coutınho, Afrânio. A literatura no Brasil. Rio de Janeiro: Sul-Americana, 1970, v. 5, p. 402-449.

Oliveira, Franklin. Graciliano Ramos: uma obra em busca de jovens leitores. O Globo, Rio de Janeiro, p. 29, 6 set. 1975.

Oliveira, Franklin. Graciliano Ramos. In: Brayner, Sônia (Org.). Graciliano Ramos. 2. ed. Rio de Janeiro: Civilização Brasileira, 1978, p. 310-316.

OliveIRA, Franklin. Literatura e civilização. Rio de Janeiro: Difel; Brasília: INL, 1978.

Oliveira, Franklin. Revolução roseana. In: Coutinho. Eduardo F. (Org.). Guimarães Rosa. 2. ed. Rio de Janeiro: Civilização Brasileira, 1991. (Fortuna crítica, v. 6).

Ramos, Ricardo. As memórias de Graciliano Ramos. O Estado de S. Paulo, São Paulo, p. 19, 13 dez. 1953.

RosA, João Guimarães. Fiç̧ão completa. Rio de Janeiro: Nova Aguilar, 2009, 2 v.

Seffrin, André et al. Mestre da crítica. Curitiba: Imprensa Oficial do Paraná; Rio de Janeiro: Topbooks, 2001.

SüSSEKIND, Flora. A crítica como papel de bala. O Globo, Blogs, 4 abr. 2010. On-line. Disponível em: <http://blogs.oglobo.globo.com/prosa/post/a-critica-como-papel-de-bala-286122.html>. Acesso em: 31 maio 2017.

Recebido em 19 de fevereiro de 2017.

Aprovado em 13 de maio de 2017.

\section{Resumo/Abstract/Resumen}

\section{As obras de Graciliano Ramos e Guimarães Rosa nos rodapés de Wilson Martins e Franklin de Oliveira}

André Barbosa de Macedo

O objetivo do artigo é abordar a maneira como se deu a recepção crítica das obras de Graciliano Ramos e Guimarães Rosa nos rodapés que Wilson Martins e Franklin de Oliveira mantinham, sob a condição de crítico titular, respectivamente nos jornais O Estado de S. Paulo (de São Paulo) e Correio da Manhã (do Rio de Janeiro).

Palavras-chave: recepção crítica, literatura brasileira, Graciliano Ramos, Guimarães Rosa.

\section{The works of Graciliano Ramos and Guimarães Rosa in footnotes of Wilson Martins and Franklin de Oliveira}

The aim of this paper is to analyze how the critical reception of Graciliano Graciliano Ramos' and Guimarães Rosa's works is developed in the footnotes published by Wilson Martins e Franklin de Oliveira, both working as main critics, respectively in the newspapers O Estado de S. Paulo (São Paulo) e Correio da Manhã (Rio de Janeiro).

Keywords: critical reception, brazilian literature, Graciliano Ramos, Guimarães Rosa. 
Las obras de Graciliano Ramos y Guimarães Rosa en los pies de página de Wilson Martins y Franklin de Oliveira

André Barbosa de Macedo

El objetivo del artículo es abordar la recepción crítica de las obras de Graciliano Ramos y Guimarães Rosa en las notas de pie de página que Wilson Martins y Franklin de Oliveira mantenían, bajo la condición de críticos titulares en los diarios O Estado de S. Paulo (de São Paulo) y Correio da Manhã (do Rio de Janeiro), respectivamente.

Palabras clave: recepción crítica, literatura brasileña, Graciliano Ramos, Guimarães Rosa. 